\title{
Structured Pharmacist-led Intervention Programme to Improve Medication Adherence in COPD Patients: A randomized controlled study
}

\author{
*Suhaj Abdulsalim, 2, Unnikrishnan Mazhuvancherry Kesavan"1,3, Manu K Mohan ${ }^{4}$, Alian A Alrasheedy ${ }^{2}$, \\ Brian Godman ${ }^{5,6}$, Donald E. Morisky 7,8 \\ ${ }^{1}$ Department of Pharmacy Practice, Manipal College of Pharmaceutical Sciences, Manipal University, \\ Manipal, India-576104. Email: s.chalil@qu.edu.sa; a.suhaj@gmail.com, * Corresponding author \\ 2Department of Pharmacy Practice, Unaizah College of Pharmacy, Qassim University, Saudi Arabia. \\ Email: Alian-A@hotmail.com \\ ${ }^{3}$ Department of Pharmacy Practice, National College of Pharmacy, Manasseri, Kozhikode, Kerala, India. \\ Email: mkunnikrishnan@gmail.com \\ ${ }^{4}$ Department of Pulmonary Medicine, Kasturba Medical College Hospital, Manipal University, Manipal, \\ India-576104. Email: manumohan73@gmail.com \\ ${ }^{5}$ Division of Clinical Pharmacology, Karolinska Institute, Stockholm, Sweden \\ ${ }^{6}$ Strathclyde Institute of Pharmacy and Biomedical Sciences, Strathclyde University, Glasgow, UK. Email: \\ Brian.Godman@ki.se; Brian.godman@strath.ac.uk \\ ${ }^{7}$ Distinguished Chair Professor at Kaohsiung University, Taiwan \\ ${ }^{8}$ Department of Community Health Sciences UCLA Fielding School of Public Health 650 Charles E. \\ Young Drive South Los Angeles. USA Email: dmorisky@ucla.edu
}

\begin{abstract}
Background: COPD, a progressive, partly reversible condition with airflow limitation particularly warrants the inclusion of pharmacists in the healthcare team. Extreme physician scarcity severely limits the implementation of quality healthcare in India. Pharmacist-led educational intervention achieves smoking cessation and improves medication adherence. Objective: This study evaluated the effectiveness of a clinical pharmacist-led intervention on medication adherence in COPD patients in a teaching hospital. Methods: In an open-labelled randomized controlled study at Kasturba Medical College Hospital, Manipal, India, patients were randomly assigned to two groups (Intervention group [IG] and Control group [CG]), and were matched for socio-demographics and clinical characteristics. Medication adherence was assessed by the Morisky, Green and Levine Medication Adherence Questionnaire (MAQ). In IG, pharmacist intervention placed emphasis on (1) compliance, (2) smoking cessation, (3) exercise, (4) inhaler use and (5) need for timely follow up. The MAQ assessment was repeated at 6, 12, 18 and 24 months. Data were analysed statistically by SPSS version 20.0. Results: Out of 328 patients screened during March 2012 to June 2013, 260 were recruited. Of these, 206 completed the follow-up (98 in CG and 104 in IG). Medication adherence improved significantly after pharmacist intervention in IG at all follow-up time points $(P<0.001)$. It increased from $49 \%$ at the baseline to $80 \%$ after 24 months $(P<0.001)$. Carelessness about taking medicines was one of the main reasons for non-adherence in COPD patients, but was effectively reduced by the intervention. Conclusions: This is the first randomized controlled trial in India that demonstrates the pivotal role of pharmacist-led educational intervention in improving medication adherence in COPD. Involving non-physician health professionals could be the best strategy, for resource-poor nations like India, because the current physician-centric healthcare has no emphasis on patient education and counseling.
\end{abstract}

Key words: Pharmacist Intervention, Medication Adherence, COPD Patients, randomized controlled study, MAQ

(Accepted for publication Journal Research in Social and Administrative Pharmacy - Please keep CONFIDENTIAL)

\section{Introduction}

Chronic obstructive pulmonary disease (COPD) is characterised by a progressive airflow limitation in the lungs, which, unlike asthma, is not fully reversible by medication. ${ }^{1}$ However, adherence to therapy improves the management of symptoms and delays disease progression. ${ }^{2}$ Patients' knowledge and awareness about the disease are also important in leading a normal life. Overall, it is estimated that the 
number of people aged 30 and over worldwide with COPD is estimated at 384 million, with a prevalence of $11.7 \%(8.4 \%-15.0 \%)^{3}$ The Global Burden of Disease Study revealed that COPD is the fourth leading cause of death worldwide, claimed 3.2 million lives in $2015,{ }^{4}$ and projected to be the third leading cause by $2030 .^{5}$ In addition to its impact on mortality, COPD is also associated with an appreciable impact on morbidity and costs. ${ }^{2,6,7-9}$ Consequently, it is a high priority area to focus on.

Adherence to medication therapy is considered a major concern. Adherence is defined as "the extent to which a person's behavior (in terms of following diets, taking medications, or executing lifestyle changes) coincides with medical or health advice." ${ }^{10}$ Patient non-adherence is one of the best recorded, but one of the least understood health-related behaviors. ${ }^{11}$ The lack of adherence to medications was described by the World Health Organization as "a new pharmacological problem". ${ }^{6}$ Moreover, substantially increasing the effectiveness of measures and interventions designed to increase patients' adherence to their therapies and recommendations may result in an impact on people's health far better than any other progress made in the therapeutic arena. ${ }^{6}$

In COPD patients, non-adherence to medication in COPD is high, with some studies showing adherence rates to inhaled and oral medications between $41 \%$ to $57 \%{ }^{2}, 12-13$ Adherence in clinical practice may be even lower at only $10 \%$ to $40 \%$ of patients with COPD. ${ }^{14-15}$ Non-adherence with their treatment recommendations can be both intentional (such as, negative attitudes to medication-taking behavior, side effects, cost, does not feel sick, etc.) and unintentional, due to reasons related to forgetting, misunderstanding, problems remembering, failure to plan ahead, etc. ${ }^{16}$ In addition, there are concerns with inhaler technique which is typically seen as sub-optimal 2,17 with adherence adversely affected if patients are using different devices requiring different techniques. ${ }^{18}$ However, it is evident that better medication adherence is associated with decrease in the number of emergency department visits and length of hospital stay among patients with chronic respiratory disease ${ }^{19}$ with improved adherence reducing costs. ${ }^{20}$

Consequently, in order for a medication to be useful, not only should the active ingredient be effective, and its delivery must be optimal, but also patients' adherence to their medications is an essential factor for success of therapy. ${ }^{6}$ Intentional non-adherence is considered an active process in which patients decide not to fill their prescribed medications. It is estimated among patients with respiratory diseases that approximately $15 \%$ of patients do not fill a new prescription and usually discontinue therapy after approximately six months. ${ }^{6}$ In contrast, unintentional non-adherence is considered as a passive process, with patients failing to take their medications and follow therapy recommendations for many reasons outside their control including old age, financial inability to buy their medicines, affecting $20 \%$ to over $50 \%$ of patients. ${ }^{6}$

In the literature, several studies have suggested that health professionals' style of communication with the patient can affect the patient's ability and tendency to adhere to their medications. ${ }^{21}$ Although health professionals are increasingly aware that non-adherence is a major health issue, individual patients may not readily disclose their non-adherence without an intervention and assessments by their health providers. ${ }^{21}$ Consequently, the role of health professionals is essential to encourage patients adherence to the therapeutic plan. ${ }^{2,6}$ For example, there is evidence that health professionals can encourage readiness to quit smoking. Wilson et al demonstrated that, even three-minutes of counselling can increase the rate of quitting by $5-10 \% .{ }^{22}$ When different health professionals such as pharmacists, doctors and nurses jointly counsel patients, the impact is typically greater. To illustrate this, the rate of quitting of smoking was enhanced when 1,723 smokers received advise from different categories of health professionals (OR 2.37; 95\% Cl 1.15-4.88). ${ }^{23}$

Providing adequate information about medications to the patients (e.g. indication of medication, clear instructions on medication use) improves adherence. ${ }^{2,} 6$ Providing tailored educational counseling raises the level of patient confidence, self efficacy, and improves their understanding on how to take their medications. ${ }^{24}$

In COPD and asthma patients, it is estimated that over $50 \%$ of them struggle to use metered-dose inhalers (MDIs) correctly. ${ }^{25}$ Each medication with its inhaler has different characteristics in terms of (1) 
internal resistance, (2) intra-thoracic deposition, (3) mechanism to check that the product was actually delivered, and (4) time and duration of action, affecting adherence in practice. ${ }^{25}$ Manual dexterity and hand strength necessary to operate the inhaler is also important, especially in the elderly. ${ }^{17}$ Poor inhaler technique and patients' beliefs about illness are associated with diminished quality of life. ${ }^{11}$ The lack of perceived benefit from therapy has also been associated with $30 \%$ of patients with COPD intentionally discontinuing their therapy. ${ }^{26}$

Whilst the exact burden of COPD in India is currently unknown ${ }^{5}$ although some studies have suggested prevalence rates of between $6.5 \%$ and $7.5 \%{ }^{27}$ prevalence rates for COPD are known to be appreciably higher in low and middle income countries such as India ${ }^{2}$ Overall, China and India appear to account for $66 \%$ of global COPD mortality. ${ }^{5,28}$ Alongside this appreciable burden, we are aware that there is currently very little published data on the impact of clinical pharmacist-led patient self-management in COPD in India. However, in other countries, published studies have shown that clinical pharmacist-led, continuous, individualized patient education that identifies and recognizes psychosocial components of patient behavior can enhance overall satisfaction with health care experience in patients with COPD. ${ }^{29-32}$ Consequently, this study aimed to evaluate the effectiveness of a structured pharmacist- led intervention programme on medication adherence in COPD patients in India.

\section{Methodology: \\ Study Design and Subjects:}

An open-labelled randomized controlled study was conducted at Kasturba Medical College Hospital, Manipal, India, over a 3 year period. Institutional ethical clearance (IEC 88/2012) was obtained prior to the study and registered with the Indian clinical trial registry (CTRI/2014/08/004848). The study subjects were selected based on inclusion criteria (confirmed diagnosis of COPD as per GOLD guidelines) and informed consent. Patients were randomized (envelop method) into two groups (Intervention group [IG] and Control group [CG]).

\section{Sample size:}

In accordance to published literature, we estimated the minimum sample size (based on measure of variation) of 100 in each group, in order to demonstrate minimum clinically significance of $5 \%$ (power $=80 \%$ ). Target sample size was estimated to be 260 patients (130 CG and 130 IG) taking into account a $30 \%$ potential dropout rate.

\section{Baseline assessment:}

Baseline data for each patient was collected using a custom designed and validated case record form. The collected data included demographic measures, disease characteristics, respiratory and nonrespiratory medications and medication regimen. The patients were also asked to complete a selfreported Morisky, Green and Levine Medication Adherence Questionnaire (MAQ). ${ }^{21}$ The reason for medication non-adherence was measured at baseline and at 24 months using a validated questionnaire.

\section{Follow up assessment:}

The medication adherence assessment was repeated at 6, 12, 18 and 24 months in both the groups.

\section{Study questionnaire:}

$M A Q$, which measures adherence through four Yes/No response items, accounts for the various reasons for non-adherence namely: forgetting, carelessness, stopping when feeling better and stopping when feeling worse. [Scoring :- 'YES'=0, 'NO'=1]. Consequently, MAQ scores range between 0 and 4 . Score of 3-4 considered as high adherence, $2=$ moderate adherence and $<2=$ low adherence.

\section{Structured Pharmacist Intervention:}

Patients' perceptions were captured accurately by one on one interviews, whenever the patients were comfortable. Patients recruited under IG were educated by the clinical pharmacist. The counselling sessions (15-20 minutes) and patient information leaflets (PILs) emphasised (1) the importance of medication compliance, (2) dose and frequency of medications, (3) need for smoking cessation, (4) simple exercise, (5) proper use of inhaler devices and (6) need for timely monitoring by the pulmonary medicine department. Each patient was followed up for a period of two years, and adherence was re- 
assessed after every six months. Patient information leaflets (PILs) describing the above techniques were developed, validated and supplied to patients for reinforcing the content delivered through counselling. Patients were further followed up by monthly telephone calls for ensuring medication adherence and timely follow ups. During follow up, patients in IG were trained for proper use of inhaler devices and were motivated for medication adherence.

\section{Control patients}

CG received standard hospital care, but did not receive the intervention by the clinical pharmacist.

\section{Development and validation of PILs:}

PILs were developed based on information collected from different sources such as "Patient UK", Micromedex, GOLD guidelines, etc. The contents of the leaflet were validated and appropriately revised by physicians. Readability of the designed PIL was calculated online (www.readability-score.com) by (1) Flesch Readability Ease (FRE) and (2) Flesch-Kincaid Grade Level (FK-GL). Baker Able Leaflets Design (BALD) was used to assess layout and design characteristics of the PILs. The details regarding development and validation of these PILs are published elsewhere. ${ }^{33}$

Data analysis:

SPSS version 20.0 were used for statistical analyses (Data screening, descriptive statistics and univariate analysis). Chi square analysis was performed to assess the significance (between CG and IG) in MAQ. A $P$ - value of $<0.05$ was considered statistically significant.

\section{Results}

The present study was carried out as part of a larger study on the impact of pharmaceutical care on outcomes in COPD patients. ${ }^{34}$

Participants Flow

Out of 328 COPD patients screened during the study period (March 2012 to June 2013), 260 were recruited. Of these, 206 patients completed follow up (98 in CG and 104 in IG). Reasons for drop out, in the decreasing order of importance were (a) lost to follow up (18 in CG and 11 in IG) (b) death (8 in CG vs 9 in IG) (c) withdrawal at different level of the study (5 in CG vs 3 in IG). Fig. 1 is a flow chart indicating patient numbers at different level of the study.

Figure 1: Flow chart indicating patient numbers at different stages of the study

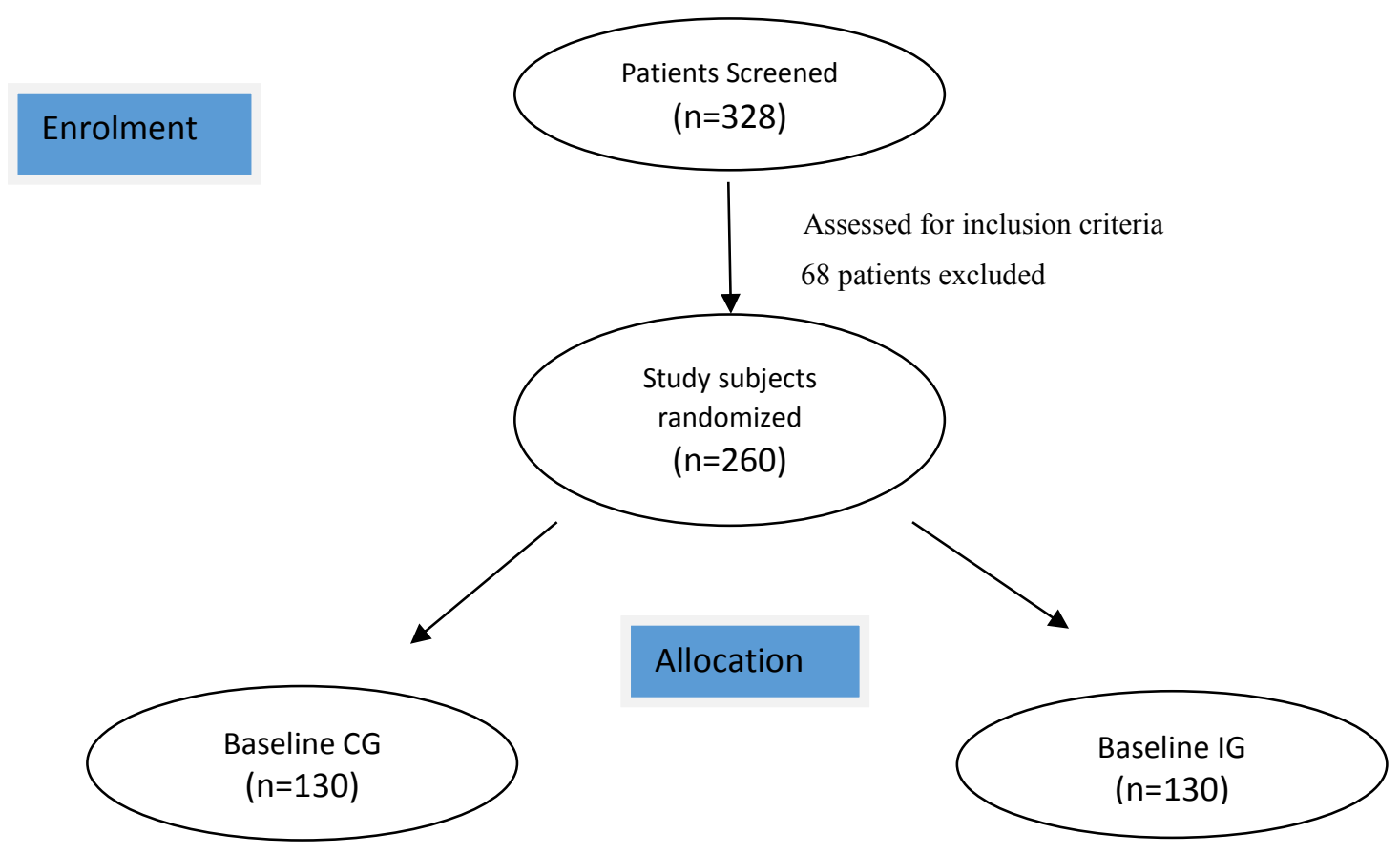




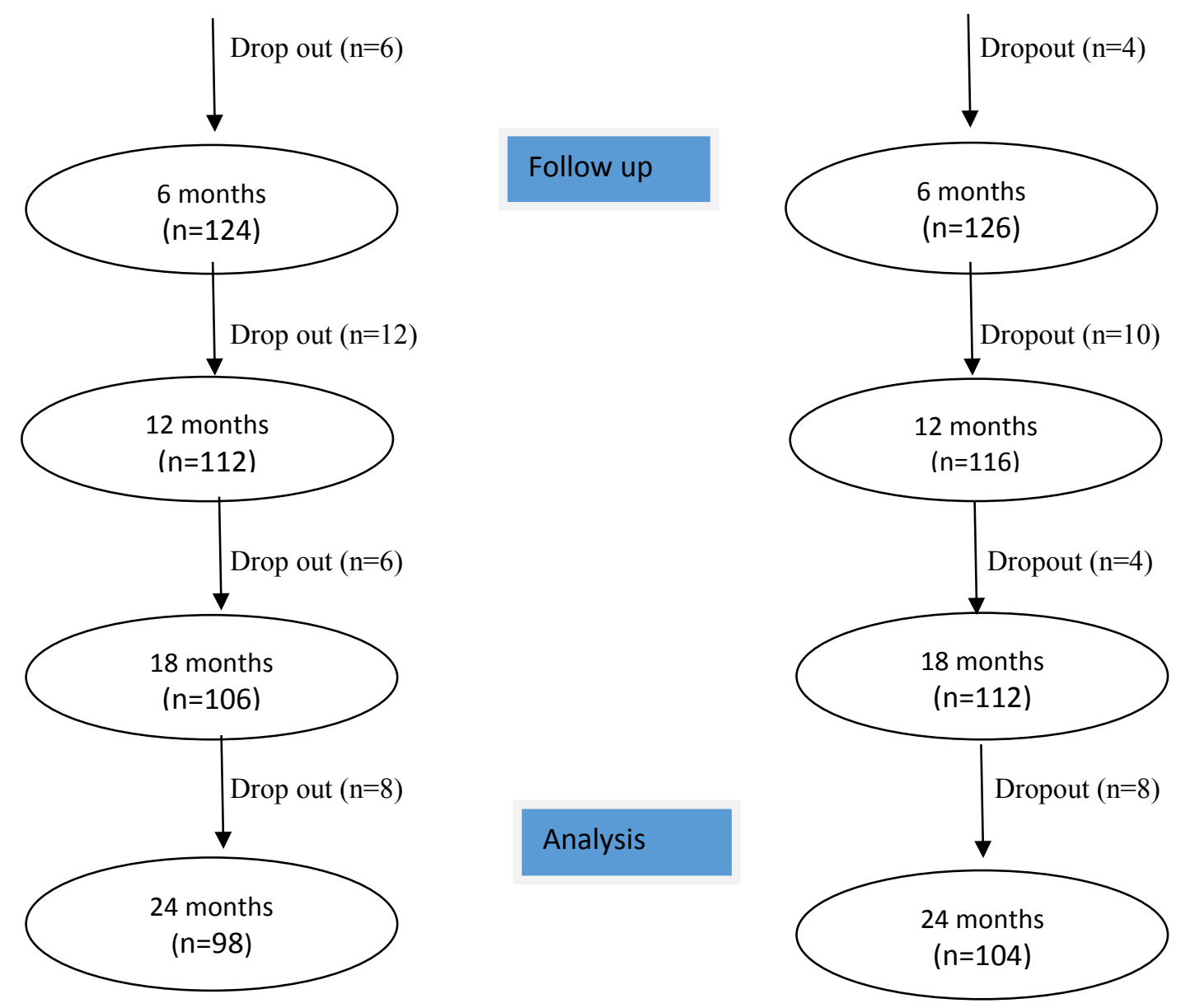

Baseline characteristics of study population:

CG and IG were matched ( $P>0.05)$ for baseline socio-demographic and clinical characteristics such as (a) mean age (61.1 \pm 8.4 vs $60.6 \pm 7.9)$, (b) male gender (94.4 vs 96.9) (c) Duration of COPD (15.3 \pm 5.7 vs 14.6 \pm 6.6$)$, (d) Mean FEV 1 (41.9 \pm 14.7 vs $44.4 \pm 14.5)$, (e) Average number of drugs used $(7.2 \pm 2.1$ vs $6.3 \pm 1.7)$, (f) co-morbidity rate ( $74 \%$ vs $69 \%)$, (g) current smokers ( $53.8 \%$ vs $56.9 \%)$. As per Kuppuswamy's socioeconomic classification, ${ }^{35}$ majority belonged to upper lower category in both groups (UG $=30.5 \%$ vs $I G=29.8 \%$ ). Pack years was estimated to be $21.7 \pm 12.6$ in $C G$ and $23.2 \pm 11.4$ in IG.

Majority of the patients belongs to GOLD III (severe) category (45.4 vs 47.6$)$. The baseline characteristics of the study population are described in Table 1. 
Table 1: Baseline characteristics of study population

\begin{tabular}{|c|c|c|c|}
\hline Characteristics & CG & IG & $P$-value \\
\hline Age $\left(\right.$ Mean \pm SD) ${ }^{\dagger}$ & $61.1 \pm 8.4$ & $60.6 \pm 7.9$ & 0.67 \\
\hline Gender (Male, \%) ${ }^{\ddagger}$ & 94.4 & 96.9 & 0.08 \\
\hline Socioeconomic status ${ }^{18}(\%)^{\ddagger}$ & \multicolumn{3}{|c|}{0.73} \\
\hline Lower & 35.8 & 37.4 & \\
\hline Upper lower & 30.5 & 29.8 & \\
\hline Middle & 23.7 & 20.6 & \\
\hline Upper middle & 7.1 & 6.4 & \\
\hline Upper & 2.9 & 5.8 & \\
\hline $\mathrm{FEV}_{1} \%$ predictedף $\left(\right.$ Mean \pm SD) ${ }^{\dagger}$ & $41.9 \pm 14.7$ & $44.4 \pm 14.5$ & 0.16 \\
\hline Smoking Status $(\%)^{\ddagger}$ & \multicolumn{3}{|c|}{0.24} \\
\hline Ex-Smoker & 43.1 & 46.2 & \\
\hline Current smoker & 56.9 & 53.8 & \\
\hline Pack years $\left(\right.$ Mean \pm SD) ${ }^{\dagger}$ & $21.7 \pm 12.6$ & $23.2 \pm 11.4$ & 0.42 \\
\hline Duration of COPD(Mean \pm SD) ${ }^{\dagger}$ & $15.3 \pm 5.7$ & $14.6 \pm 6.6$ & 0.36 \\
\hline Severity as per GOLD (\%) ${ }^{\ddagger}$ & \multicolumn{3}{|c|}{0.34} \\
\hline Mild & 12.7 & 13.8 & \\
\hline Moderate & 21.9 & 20.1 & \\
\hline Severe & 45.4 & 47.6 & \\
\hline Very severe & 20.0 & 18.5 & \\
\hline No. of Medications (Mean \pm SD) ${ }^{\dagger}$ & $7.2 \pm 2.1$ & $6.3 \pm 1.7$ & 0.68 \\
\hline Co morbid conditions (\%) ${ }^{\ddagger}$ & 74 & 69 & 0.64 \\
\hline
\end{tabular}

NB: IG- Intervention group, CG- Control group, SD- standard deviation, FEV 1 -Forced expiratory volume in one second, COPD-Chronic Obstructive Pulmonary Disease, GOLD- Global Initiative for Chronic Obstructive Lung Disease; ${ }^{\circ}$ Data were analysed by $t$ test ; $¥$ Data were analysed by Chi square; $\mathbb{T}$ FEV 1 calculated based on spirometry.

Outcomes and estimations

Medication adherence of COPD patients at different time interval:

At the baseline, MAQ scores were compared between CG and IG ( $P>0.05)$. In IG, MAQ improved significantly after the pharmacist intervention at follow-up $(P<0.001)$. The best improvement was noted at 24 months, giving a picture of wholesome improvement. Medication adherence of COPD patients at different time intervals are shown in Table 2. Mean MAQ scores of COPD patients are depicted in Table 3. 
Table 2: Medication adherence of COPD patients at different time interval

\begin{tabular}{|c|c|c|c|}
\hline$\%$ Adherence $^{\dagger}$ & $\begin{array}{l}\text { CG } \\
\text { n (\%) }\end{array}$ & $\begin{array}{l}\text { IG } \\
\text { n (\%) }\end{array}$ & $P$-Value \\
\hline $\begin{array}{l}\text { Baseline } \\
\text { High-Adherence } \\
\text { Moderate-adherence } \\
\text { Low-adherence }\end{array}$ & $\begin{array}{l}62(47.7) \\
32(24.6) \\
36(27.7)\end{array}$ & $\begin{array}{l}63(48.5) \\
31(23.8) \\
36(27.7)\end{array}$ & 0.988 \\
\hline $\begin{array}{l}6 \text { months } \\
\text { High-Adherence } \\
\text { Moderate-adherence } \\
\text { Low-adherent }\end{array}$ & $\begin{array}{l}60(48.4) \\
30(24.2) \\
34(27.4)\end{array}$ & $\begin{array}{l}98(77.1) \\
18(14.2) \\
11(8.7)\end{array}$ & $<0.001^{*}$ \\
\hline $\begin{array}{l}12 \text { months } \\
\text { High-Adherence } \\
\text { Moderate-adherence } \\
\text { Low-adherence }\end{array}$ & $\begin{array}{l}55(49.1) \\
26(23.2) \\
31(27.7)\end{array}$ & $\begin{array}{l}90(77.6) \\
17(14.7) \\
9(7.8)\end{array}$ & $<0.001^{*}$ \\
\hline $\begin{array}{l}18 \text { months } \\
\text { High-Adherence } \\
\text { Moderate-adherence } \\
\text { Low-adherence }\end{array}$ & $\begin{array}{l}51(48.1) \\
25(23.6) \\
30(28.3)\end{array}$ & $\begin{array}{l}89(79.5) \\
15(13.4) \\
8(7.1)\end{array}$ & $<0.001^{*}$ \\
\hline $\begin{array}{l}24 \text { months } \\
\text { High-Adherence } \\
\text { Moderate-adherence } \\
\text { Low-adherence }\end{array}$ & $\begin{array}{l}48(49) \\
23(23.5) \\
27(27.4)\end{array}$ & $\begin{array}{l}84(80.8) \\
12(11.5) \\
8(7.7)\end{array}$ & $<0.001^{*}$ \\
\hline
\end{tabular}

NB: CG-Control group, IG-Intervention group, n-Number of patients; † Data were analysed by Chi-square; *statistically significant

Table 3: Mean MAQ score of COPD patients at different time interval.

\begin{tabular}{|l|l|l|l|l|l|}
\hline Group & $\begin{array}{l}\text { Baseline } \\
\mathbf{( 9 5 \%} \mathbf{C I})\end{array}$ & $\begin{array}{l}\mathbf{6} \text { months } \\
\mathbf{( 9 5 \%} \mathbf{~ C l})\end{array}$ & $\begin{array}{l}\mathbf{1 2} \text { months } \\
\mathbf{( 9 5 \% ~ C l )}\end{array}$ & $\begin{array}{l}\mathbf{1 8} \text { months } \\
\mathbf{( 9 5 \% ~ C l )}\end{array}$ & $\begin{array}{l}\mathbf{2 4} \text { months } \\
\mathbf{9 5} \% \mathbf{C I})\end{array}$ \\
\hline IG & 1.76 & 1.12 & 1.09 & 1.04 & 0.98 \\
& $(1.56-1.96)$ & $(0.96-1.28)$ & $(0.92-1.25)$ & $(0.88-1.19)$ & $(0.81-1.15)$ \\
\hline CG & 1.80 & 1.79 & 1.79 & 1.80 & 1.78 \\
& $(1.60-2.00)$ & $(1.58-2.00)$ & $(1.58-2.01)$ & $(1.57-2.03)$ & $(1.53-2.02)$ \\
\hline
\end{tabular}

NB: CG-Control group, IG-Intervention group, Cl-Confidence Interval

Reasons for Non-adherence among COPD Patients:

At baseline, we found that, stop taking when feel better as the major intentional reason for non-adherence in COPD patients (17.6\% in CG vs $16.6 \%$ in IG). Among unintentional reasons, the carelessness about taking medicines (23.5\% in CG vs $25.6 \%$ in IG) and high cost of medicines (5.9\% in CG vs $7.6 \%$ in IG) were the major reasons for non-adherence. At 24 months follow up, in IG, intentional reasons for nonadherence were decreased appreciably compared to CG. Table 4 describes various reasons for nonadherence among COPD patients. 
Table 4: Reasons for Non-adherence among COPD Patients

\begin{tabular}{|l|c|c|c|c|}
\hline \multirow{2}{*}{ Reason for non-adherence } & \multicolumn{2}{|c|}{ Baseline } & \multicolumn{2}{c|}{24 Months } \\
\cline { 2 - 5 } & $\begin{array}{c}\mathrm{CG}(\mathrm{N}=68) \\
\mathrm{n}(\%)\end{array}$ & $\begin{array}{c}\text { IG (N=66) } \\
\mathrm{n}(\%)\end{array}$ & $\begin{array}{c}\text { CG (N=50) } \\
\mathrm{n}(\%)\end{array}$ & $\begin{array}{c}\text { IG (N=21) } \\
\mathrm{n}(\%)\end{array}$ \\
\hline \begin{tabular}{|l|c|c|}
\hline Intentional \\
Stop taking medicines when feel better
\end{tabular} & $12(17.6)$ & $11(16.6)$ & $8(16)$ & $1(4.8)$ \\
\hline Stopping when feeling worse & $8(11.7)$ & $9(13.6)$ & $6(12)$ & $1(4.8)$ \\
\hline Forget to take medicines & $7(10.4)$ & $6(9.1)$ & $5(10)$ & $2(9.5)$ \\
\hline Not beneficial & $6(8.8)$ & $5(7.6)$ & $5(10)$ & $1(4.8)$ \\
\hline Fear of side effects & $5(7.4)$ & $3(4.5)$ & $3(6)$ & $1(4.8)$ \\
\hline Fear of becoming dependent on treatment & $4(5.9)$ & $4(6.1)$ & $4(8)$ & $1(4.8)$ \\
\hline Unintentional & $16(23.5)$ & $17(25.6)$ & $12(24)$ & $2(9.5)$ \\
\hline Carelessness about taking medicines & $4(5.9)$ & $5(7.6)$ & $3(6)$ & $6(28.5)$ \\
\hline High cost of medicines & $2(2.9)$ & $2(3.1)$ & $2(4)$ & $2(9.5)$ \\
\hline Running out of medicines & $3(4.4)$ & $2(3.1)$ & $1(2)$ & $2(9.5)$ \\
\hline Complex dosing regimens & $1(1.5)$ & $2(3.1)$ & $1(2)$ & $2(9.5)$ \\
\hline Old Age & $68(100)$ & $66(100)$ & $50(100)$ & $21(100)$ \\
\hline Total
\end{tabular}

NB: CG- Control group, IG-Intervention group, N- Total Number of non-adherent patients, n- Number of patients

\section{Discussion}

Pharmacists can prevent drug-related problems and achieve optimal outcomes from drug therapy, especially in chronic diseases. ${ }^{36}$ To the best of our knowledge, this is the first randomized controlled study from India that demonstrates the value of a structured pharmacist-led programme on medication adherence in COPD patients. Even those few Indian studies that previously evaluated adherence rates in patients with COPD are either cross-sectional or observational without considering pharmacist interventions. ${ }^{37-40}$ Our study findings highlight the importance of patient-education by pharmacist in India.

The suboptimal role played by pharmacists in educating, motivating and counselling patients is evident from the fact that COPD patients in India are mostly current smokers while those from Northern Ireland are ex-smokers. ${ }^{31,37-39}$ Educational intervention is an economical and feasible strategy, especially in the context of the ever-increasing burden of non-communicable disease in resource-poor developing nations like India..$^{41}$ Our results (Table 2 and 3 ) revealed that, medication adherence can be improved significantly $(P<0.001)$ in COPD patients by structured pharmacist-led intervention. Gallefos et al demonstrate that, an individualized treatment plan with a self-management training programme, by a nurse / physiotherapist, can also improve patient outcomes in COPD within one year. ${ }^{30}$ Previous studies by Mahour et al and Jarab et al demonstrated that pharmacist-led intervention improved medication adherence in COPD patients in Northern Ireland and Jordan respectively. ${ }^{29,} 31-32$

Patients often lack adequate knowledge about the symptoms and exacerbations of their disease and how to deal appropriately in such situations. ${ }^{42}$ However, when patients are given an opportunity to identify $/$ discuss their concerns about medications and/or life style, fears can be allayed and barriers can be identified. ${ }^{43}$ This in turns could improve the adherence, given the fact that medication adherence in COPD is generally poor. ${ }^{43}$ Most frequent reasons for non-adherence in our study, at baseline, in IG, were carelessness $(25.6 \%)$, stopping when they 'feel better' (16.6\%), stopping when 'feel worse' $(13.6 \%)$ and forgetting (9.1\%). This is consistent with previous studies. ${ }^{6,4}$ Intentional reasons for non-adherence decreased more appreciably than unintentional reasons, validating the substantial role of structured clinical pharmacist-led intervention in our study (Table 4).

Overall, the efforts to improve adherence in COPD patients should focus on maintaining clinical significant improvements in health status, prevent exacerbations of the disease and hence reducing the associated healthcare costs, rather than merely mandating compliance to healthcare professionals instructions.$^{24}$ It is evident in literature that health professionals contribute to patients' perception of their 
disease, medications and, eventually, their adherence. Previous reports have endorsed the strategies employed in our study to improve medication adherence, namely (1) continuous monitoring of care (2) explaining the rationale for prescription (3) providing information in both written and verbal forms about disease and drug regimens, (4) assessment of medication adherence (5) follow-up supervision and (6) participation in self-management programmes. ${ }^{24,45-46}$ Consequently, this is an area to focus on in the future.

This especially because WHO's World Medicine Situation 2011 report indicated that in developing countries such as India, dispensing time is only 60 seconds, with one third of the patients leaving the health facility without understanding their prescriptions and up to $50 \%$ of dispensed medicines not even labelled. ${ }^{47}$ In developed countries, for example US, Wilson et al. demonstrated that approximately onethird of patients did not talk to their doctor about their medicines during the last 12 months. ${ }^{48}$ Over the years, several studies showed that a considerable proportion of patients receive little instructions on how to take new medications. ${ }^{49-50}$ Overworked physicians and paucity of trained doctors in resource-poor settings obligate task-sharing to non-physician healthcare providers like clinical pharmacists, who can simplify treatment regimens and enhance compliance. Task sharing is both feasible and less resource intensive and would go a long way in the management of COPD based on our and other findings.

\section{Conclusion}

Enhancing patient self-efficacy as part of self-management education is important to promote long term adherence. Shared decision making during the initial and regular follow-up visits helps to augment the partnership between patient and physician, thereby facilitating adherence, improving patient outcomes thereby diminish the economic and societal burden associated with COPD. Consequently, pharmacist involvement could play a pivotal role in improving medication adherence in COPD. Involving nonphysician health professionals could be the best strategy, for resource-poor nations like India, because the current physician-centric healthcare has no emphasis on patient education and counseling.

\section{Acknowledgements}

We would like to show our gratitude to Manipal College of Pharmaceutical Sciences, Kasturba Hospital, Manipal, and Manipal University, India for their support.

\section{Conflict of Interest}

The authors declare that they have no conflict of interest.

\section{Funding}

None

\section{References}

1. Global strategy for the diagnosis, management and prevention of chronic obstructive pulmonary disease. Global Initiative for Chronic Obstructive Lung Disease: [updated January 2017; cited 10 May 2017]. Available from: http://www.goldcopd.org/

2. Bryant J, McDonald VM, Boyes A, et al. Improving medication adherence in chronic obstructive pulmonary disease: a systematic review. Respir Res 2013;14:109.

3. Adeloye D, Chua S, Lee C, et al. Global and regional estimates of COPD prevalence: Systematic review and meta-analysis. J Glob Health 2015;5:020415.

4. Country statistics and global health estimates by WHO and UN partner. [updated 2017; cited on 10 May 2017] Available from http://who.int/gho/mortality burden disease/en/

5. Rajkumar P, Pattabi K, Vadivoo S, et al. A cross-sectional study on prevalence of chronic obstructive pulmonary disease (COPD) in India: rationale and methods. BMJ open 2017;7:e015211.

6. Sanduzzi, Alessandro, Piero B, et al. COPD: adherence to therapy. Multidisciplinary respiratory medicine 2014; 9: 60.

7. Jones PW, Brusselle G, Dal Negro RW, et al. Health-related quality of life in patients by COPD severity within primary care in Europe. Respir Med 2011;105.

8. Qaseem A, Wilt TJ, Weinberger SE, et al. Diagnosis and management of stable chronic obstructive pulmonary disease: a clinical practice guideline update from the american college of physicians, 
american college of chest physicians, american thoracic society, and european respiratory society. Ann Intern Med 2011;155.

9. Chen W, FitzGerald JM, Sin DD, et al. Excess economic burden of comorbidities in COPD: a 15-year population-based study. Eur Respir J 2017;50(1).

10. Haynes RB, Taylor DW, Sackett DL. Compliance in healthcare. Baltimore. Johns Hopkins University Press 1979; 1-7.

11. George J, David CM, Thoman R, et al. Factors associated with medication nonadherence in patients with COPD. Chest 2005; 128:3198-3204.

12. Bosley C, Corden Z, Rees $P$, et al. Psychological factors associated with the use of home nebulized therapy for COPD. Eur Respir J 1996;9.

13. Taylor DR, Kinney CD, McDevitt DC. Patient compliance with oral theophylline therapy. Br J Clin Pharmacol 1984;17.

14. Restrepo RD, Alvarez MT, Wittnebel LD, et al. Medication adherence issues in patients treated for COPD. Int J Chron Obstruct Pulmon Dis 2008;3.

15. Charles MS, Blanchette $\mathrm{CM}$, Silver $\mathrm{H}$, et al. Adherence to controller therapy for chronic obstructive pulmonary disease: a review. Curr Med Res Opin. 2010;26:2421-9

16. Dolce JJ, Crisp C, Manzella B, et al. Medication adherence patterns in chronic obstructive pulmonary disease. Chest 1991; 99:837-41.

17. Barrons R, Pegram A, Borries A. Inhaler device selection: special considerations in elderly patients with chronic obstructive pulmonary disease. Am J Health Syst Pharm. 2011;68:1221-32.

18. Bosnic-Anticevich $\mathrm{S}$, Chrystyn $\mathrm{H}$, Costello RW, et al. The use of multiple respiratory inhalers requiring different inhalation techniques has an adverse effect on COPD outcomes. Int $J$ Chron Obstruct Pulmon Dis. 2017; 12:59-71.

19. Balakrishnan R, Christensen DB. Inhaled corticosteroid use and associated outcomes in elderly patients with moderate to severe chronic pulmonary disease. Clin Ther 2000; 22:452- 469.

20. Darbà J, Ramírez G, García-Rivero JL, et al. Estimating the economic consequences of an increased medication adherence due to a potential improvement in the inhaler technique with Spiromax(®) compared with Turbuhaler $(\mathbb{B})$ in patients with moderate-to-severe chronic obstructive pulmonary disease in Spain. Clinicoecon Outcomes Res 2017;9:127-37.

21. Morisky DE, Green LW, Levine DM. Concurrent and predictive validity of a self-reported measure of medication adherence. Med Care 1986; 24: 67-74.

22. Wilson DH, Wakefield MA, Steven ID, Rohrsheim RA, Esterman AJ, Graham NM. Sick of smoking: evaluation of a targeted minimal smoking cessation intervention in general practice. Med J Aust 1990; 152: 518-521.

23. An LC, Foldes SS, Alesci NL, Bluhm JH, Bland PC, Davern ME. The impact of smoking-cessation intervention by multiple health professionals. Am J Prev Med 2008; 34: 54- 60.

24. Bourbeau J, Bartlett S J. Patient adherence in COPD. Thorax 2008; 63:831-838.

25. Federico L. Inhaled Drug Delivery in the Hands of the Patient. Journal of Aerosol Medicine and Pulmonary Drug Delivery. 2014; 27: 414-418.

26. Giraud V, Roche N. Misuse of corticosteroid metered-dose inhaler is associated with decreased asthma stability. Eur Resp J 2002; 19:246-251.

27. McKay AJ, Mahesh PA, Fordham JZ, et al. Prevalence of COPD in India: a systematic review. Prim Care Respir J. 2012;21:313-21.

28. Salvi SS, Manap R, Beasley R. Understanding the true burden of COPD: the epidemiological challenges. Prim Care Respir J. 2012;21:249-51.

29. Jarab AS, Salam GA, Khdour M, et al. Impact of Pharmaceutical care on health outcomes in patients with COPD. Int J Clin Pharm 2012; 34:53-62.

30. Gallefoss F. The effects of patient education in COPD in a 1-year follow-up randomised, controlled trial. Patient Educ Couns 2004; 52:259-66.

31. Khdour M, Kidney JC, Smyth BM, et al. Clinical Pharmacy -led disease and medicine management programme for patients with COPD. Br J Clin Pharmacol 2009; 68:588-98.

32. Tommelein E, Mehuys E, Van Hees T, et al. Effectiveness of pharmaceutical care for patients with chronic obstructive pulmonary disease (PHARMACOP): a randomized controlled trial. $\mathrm{Br} \mathrm{J}$ Clin Pharmacol 2014;77:756-66. 
33. Suhaj A, Mohan MK, Mohapatra A, et al. Development and Readability Assessment of Patient Information Leaflets for Chronic Obstructive Pulmonary Disease. Asian J. Pharm. Hea. Sci 2015; 5:1237-1241.

34. Suhaj A, Manu MK, Unnikrishnan MK, et al. Effectiveness of clinical pharmacist intervention on health related quality of life in chronic obstructive pulmonary disorder patients - a randomized controlled study. J Clin Pharm Ther. 2016; 41, 78-83

35. Ravikumar BP, Shankar RD, Rao AR. Kuppuswamy's socio-economic status scale - a revision of economic parameter for 2012. International Journal of Research and Development of Health 2013;1: 2-4.

36. Vanitha RN, Thomas $\mathrm{R}$, Rohini $\mathrm{E}$, et al. A study on drug related problems in chronic kidney disease patients of a tertiary care teaching hospital in south India. World Journal of Pharmaceutical Research 2014; 3: 1403-17.

37. Kumar S, Matreja PS, Gupta AK, et al. To Assess the Quality of Life (QOL) of Caregivers and Patients Suffering from Chronic Obstructive Pulmonary Disease (COPD). J Aller Ther 2012; S2:003.

38. Prakash B, Puri MM, Kumar L, et al. Correlation of quality of life and activities of daily living with disease stage in patients with COPD. Int J Med Public Health 2014; 4:275-79.

39. Agrawal SR, Joshi R, Jain A. Correlation of severity of chronic obstructive pulmonary disease with health-related quality of life and six-minute walk test in a rural hospital of central India. Lung India 2015; 32:233-40.

40. Fugate AR, Kadam AM, Ganachari MS. Prospective study of medication adherence pattern in chronic obstructive pulmonary disease and asthma patient's in tertiary care teaching hospital. Indian Journal of Pharmacy Practice 2015; 8: 78-83.

41. Sharma A, Ladd E, Unnikrishnan MK. Healthcare Inequity and Physician Scarcity Empowering NonPhysician Healthcare. Economic and political weekly, 2013; XLVIII(13):112-17.

42. Kessler R, Stahl E, Vogelmeier C, et al. Patient understanding, detection, and experience of COPD exacerbations: an observational, interview-based study. Chest 2006;130:133-42.

43. Make BJ. Chronic obstructive pulmonary disease: developing comprehensive management. Respir Care 2003; 48:1225-34.

44. Coutts JA, Gibson NA, Paton JY. Measuring compliance with inhaled medication in asthma. Arch Dis Child 1992; 67:332-33.

45. Tashkin DP. Multiple dose regimens. Impact on compliance. Chest 1995; 107 (5 Suppl):176-182.

46. Morris LA, Halperin JA. Effects of written drug information on patient knowledge and compliance: a literature review. Am J Public Health 1979; 69:47-52.

47. "The World Medicines Situation Report", World Health Organisation 2011.[updated on 2013; Cited on 10 May 2017] Available from http://www.who.int/medicines/areas/policy/world medicines situation/en/index.html

48. Wilson IB, Schoen C, Neuman P, et al. Physician-patient communication about prescription medication nonadherence: a 50-state study of America's seniors. J Gen Intern Med 2007; 22:6-12.

49. Morris LA, Tabak ER, Gondek K. Counseling patients about prescribed medication: 12-year trends. Med Care 1997; 35:996-1007.

50. Stewart JE, Martin JL. Correlates of patients' perceived and real knowledge of prescription directions. Contemp Pharm Pract 1979; 2:144-48. 
